\title{
Incubation in one-trial passive avoidance learning: A cautionary note'
}

WILLIAM I. RIDDELL ${ }^{2}$ and TERRY HERMAN, University of Connecticut, Storrs, Connecticut

Sixty rats were tested in a step-down passive avoidance learning situation in an attempt to define an incubation gradient when the effects of the heightened activity following the training trial were controlled. At training test intervals of $5 \mathrm{sec}, 10 \mathrm{sec}$, and $3 \mathrm{~h}$ 1-trial learning was observed in the experimental groups in which the effects of activity were controlled, while the typical incubation gradient was observed in the absence of control over activity.

It has been recently reported (Pinel \& Cooper, 1966; McGaugh, 1966) that in one-trial passive avoidance learning situations incubation of the learned response occurs during the interval usually considered as being associated with short-term memory. In both of these investigations a positive relationship between memory strength and training-test interval was reported. Although the critical temporal parameters varied between studies, a result not unexpected considering the task differences, both studies reported that there was no significant avoidance for at least $10 \mathrm{sec}$ following the training trial.

An alternative explanation for the failure of Ss to give evidence of a read-out from short-term memory involves the postulation of a variable uncontrolled in either the Pinel \& Cooper (1966) or McGaugh (1966) investigations, i.e., activity; a variable long considered in assessing incubation effects in active avoidance learning (Kamin, 1967). It is suggested that the interaction between the task parameter and general activity level could account for the previously reported results. Although correct solution to an active avoidance task could be facilitated by increases in general activity, increases in general activity could mask the correct response in many passive avoidance learning situations. As any heightened general activity would dissipate with time following the learning trial, the increase in retention reported by Pinel \& Cooper (1966) and McGaugh (1966) would be expected, if it is assumed that the strength of the learned response is constant, and activity merely exerted a masking effect.

The present experiment was designed to test the degree to which general heightened activity following the training trial contributes to the reported incubation effect in passive avoidance learning. It was hypothesized that in those conditions in which the effect of activity is controlled there will be no differences in the retention of the avoidance response as a function of time.

\section{SUBJECTS}

Sixty male hooded rats of the Long-Evans strain were used in the experiment. The animals were obtained from a commercial supplier (Research Animals, Inc., Pittsburgh, Pa.) or were raised in the laboratory from animals originally obtained from the same source. At the time of testing Ss were between 80-100 days old. During the time Ss were tested they were housed individually in standard wire-mesh cages, and provided with ad lib access to food and water.

\section{APPARATUS}

The step-down apparatus employed was identical to the one described by Chorover \& Schiller (1965) except that in the confined condition the step-down platform was placed in the corner of the apparatus, and was enclosed by a transparent guillotine door which extended to the top of the apparatus. To facilitate the replacement of Ss on the platform in the confined condition a harness (cat collar) was employed. The harness allowed the $E$ to raise the $S$ above the platform, replace the guillotine door, and place the $S$ back on the platform with a minimum of additional trauma following the training trial in the confined condition.

\section{PROCEDURE}

The Ss were initially divided into Confined (C) and Nonconfined (NC) groups. Each group of $30 \mathrm{Ss}$ was further partitioned, on the basis of SDLs on Trials $1-4$, into three groups of $10 \mathrm{Ss}$ each. The only distinction between these latter three groups was the retention interval interposed between the training trial and test trial, i.e., $5 \mathrm{sec}, 10 \mathrm{sec}$, or $3 \mathrm{~h}$.

The procedure employed for $\mathrm{Ss}$ in the $\mathrm{C}$ and $\mathrm{NC}$ condition was patterned after the procedure reported by Riddell (1968). At the start of each trial $S$ was placed in the center of the raised platform, and the time required for $S$ to place both front feet on the grid floor was recorded. Approximately $10 \mathrm{sec}$ after stepping down $S$ was removed from the apparatus and returned to the home cage. In order to establish baseline information each $S$ was given four habituation trials at the rate of one trial per day. On Trial 5 when $S$ stepped from the platform a $1 \mathrm{~mA}$ foot-shock was administered for 2 sec. For Ss in the (C) condition SDL was measured from the raising of the guillotine door. The $S s$ in the (C) condition were initially placed on the platform and retrieved following each trial via a string attached to the harness.

Following the training trial Ss were tested for passive avoidance of the grid floor after $5 \mathrm{sec}, 10 \mathrm{sec}$, or $3 \mathrm{~h}$. In the (C) condition the $S$ was returned to the platform via the harness and the guillotine door was lowered following the training trial. The guillotine door was then raised either 5 or $10 \mathrm{sec}$ following the onset of the foot-shock, and SDLs were recorded. In the (NC) condition the $S$ was placed by hand on the platform either 5 or 10 sec following the foot-shock; SDL in this condition were measured from time of "release." All Ss in the $\mathbf{3}$ h conditions were returned to the home cage following the shock-trial, and tested in the standard manner $3 \mathrm{~h}$ later. If, on Trial $6, \mathrm{~S}$ remained on the platform for $5 \mathrm{~min}$ the trial was terminated.

\section{RESULTS AND DISCUSSION}

Skewness in the distribution of latency scores indicated the use of nonparametric statistical analysis. The performance of Ss was compared by means of a series of Mann-Whitney $U$ tests (intergroup comparisons) and Wilcoxon Matched-Pairs SignedRanks Test (intragroup comparisons). Two-tailed tests were used throughout. The effects of the different treatments are presented graphically in Fig. 1.

As is evident from Fig. 1 one general effect of the differences between the $\mathrm{C}$ and $\mathrm{NC}$ condition was to produce a significant difference between baseline latencies $(p<.001)$ on Trials 3-5. Although there were no significant differences within the $\mathrm{NC}$ group across Trials 3-5, there was a significant increase in latency from Trial 3 to $5(p<.05)$ in the $C$ group.

In agreement with previous results the latencies in the NC group appear to incubate over time. Although there is no significant difference between the median SDL on Trials 3-5 and the retention test for the $5 \mathrm{sec}$ NC group, there is a significant increase over baseline performance in the $10 \sec (p<.05)$ and $3 \mathrm{~h} \mathrm{NC}$

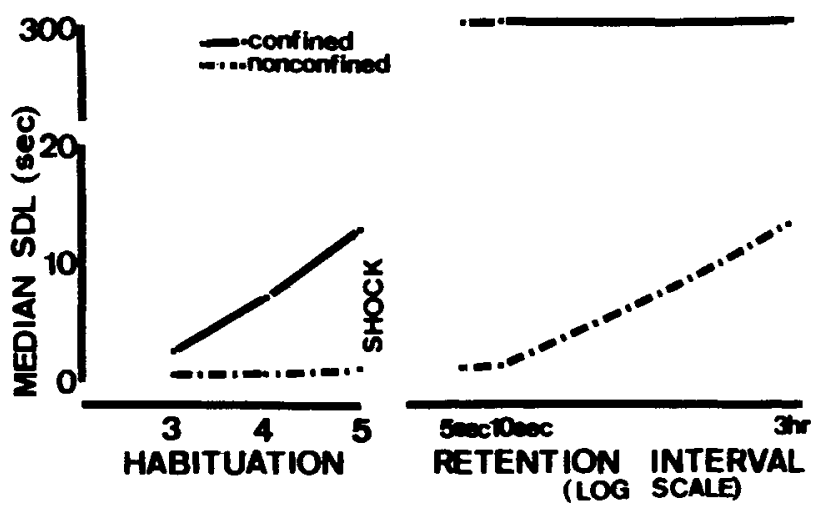

Fig. 1. Median step-down batency for alf groups on the habituation and test trials. 


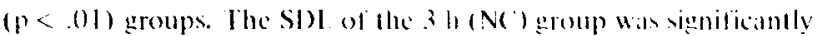
longer $(p<.002)$ from both the 5 sec and 10 sec gromps. Which in turn did not differ from each olacr. When one comsiders the performance of the Ss in the (" condition. however. it is apparent that some additional varialble. other than memory. resulted in the decrement in the 5 and $10 \mathrm{sec} N($ groups. Since there are no significant differences between the sec, 10 sec, and 3 ho $C$ groups. and all groups differ from both their baseline performanes $(p<.001)$ and the comparable groups in the NC condition $\left(p<.00^{2}\right)$ any incubation interpretation of the data is untenable. The significant difference between the 3 h groups probably reflects an intrinsic difference between conditions. a conclusion supported by the habituation data as general activity should be negligible at this point. Although it is possible to argue that a ceiling effect was operating in the $C$ condition thereby obscuring any incubation gradient it seems that this line of reasoning is minimized by the exceptionally long criterion employed. i.e., 5 min. It should also be noted even $S$ in the $(C)$ condition which did not show an increass in SDL on the habituation trials conformed to the pattern of results just reported.

In an attempt to partial out the factor in the $\mathrm{C}$ condition which resulted both in longer latencies on habituation trials and superior avoidance performance several additional groups were tested. The results indicated that although no one factor was completely responsible for the differing performance levels the presence or absence of the guillotine door seemed to be the key ingredient.

\section{SUMMARY}

In general the results of this investigation suggest that when the elfect of aletivity is minimised there is no evidence for cither at incubation gradient or any teficit in retrieval immedialely following the learming triat. In this respect it is essential that future investigations adecaltely account for this factor before ascribing their results to any memory process.

\section{REFERENCLS}

CHOROVER. S. L.. \& SCHILLER, P. II. Short-tem retrograde annesiat in rats. Journal of Comparative \& Physiological Psychology, 1965. 59, 73-78.

KAMIN. L. J. The relention of incompletely learned avoidance responses. Jounal of Comparative Pliysiology, 1957, 50, 457-460.

McGAUGH, J. L. Time dependent processes in memory storage. Science, $1966,153,1351.1358$.

PINEL. J. P. J., \& COOPER, R. M. Incubation and its implications for the interpretation of the ECS gradient effect. Psychonomic Science, 1966, 63. 123-124.

RIDDELL, W. I. The effect of electroconvulsive shock: Permanent or temporary amnesia. Journal of Comparative \& Pliysiological Psych ology, in press.

\section{NOTES}

1. This research was supported in part by NIH Grant No. 10972, William A. Wilson, Jr., principal investigator.

2. Now at the State University of New York, at Brockport. 